Information gained by a professional man in the course of a relationship with a client is the property of the client. The ethical rule is clear. Information so gained should not be passed on to others without the owner's consent save in certain defined circumstances. Doctors, for example, have a statutory obligation to notify certain infectious diseases. Here the interests of society outweigh those of the patient. Other instances occur in which medical men must on their own responsibility weigh their ethical duty to their patients against another but secondary duty as citizens to prevent harm befalling others. Hippocrates must have had these situations in mind when he defined the things seen or heard in practice (or even outside practice in social intercourse) that ought not to be divulged as those "that ought not to be published abroad." 3 Commonly cited examples of secrets that might be divulged are the case of a nursemaid with gonorrhoea who refuses treatment and the epileptic driver who insists on continuing to drive against his doctor's advice.

The B.M.A.'s ethical rule on professional secrecy is stated in the following paragraph:

"It is a practitioner's obligation to observe the rule of professional secrecy by refraining from disclosing voluntarily without the consent of the patient (save with statutory sanction) to any third party information which he has learnt in his professional relationship with the patient."

A second paragraph was added by the Representative Body in 1959 as follows:

"The complications of modern life sometimes create difficulties for the doctor in the application of the principle, and on certain occasions it may be necessary to acquiesce in some modification. Always, however, the overriding consideration must be the adoption of a line of conduct that will benefit the patient, or protect his interests."

This somewhat obscures the issue, because it fails, perhaps intentionally, to give any hint of what complications of modern life the Representative Body had in mind. The General Medical Council, ${ }^{5}$ in its booklet on its functions, procedure, and disciplinary jurisdiction, lists " improperly disclosing information obtained in confidence from a patient" as an example of abuse of the relationship between doctor and patient.

It is healthy for a profession to take stock from time to time of its ethical positions. Ethical rules are not immutable. Like the common law and social mores they are subject to evolutionary processes in response to the development of the society in which they exist to serve. The Hippocratic Oath has survived largely intact in its application because its guidance is of a kind to attract the loyalty of succeeding generations of thinking medical men. Rules of conduct that do not appeal to the majority will always be disobeyed. The boundary between what is ethical and unethical is often hard to define. Within the ethos of the body professional to which all its members owe allegiance a wide spectrum of conduct is possible, which may range from that which may be unhesi-

\footnotetext{
1 Lord Moran, Winston Churchill: The Struggle for Survival, 19401965, 1966. Constable, London.

2 Sunday Times, 10 April, 17 April, 24 April, 1 May, 8 May, 15 May, and 22 May 1966.

s Jones, W. H. S., The Doctor's Oath, 1924. Cambridge University Press. Quoted in Brit. med. F., 1948, 2, 616.

- British Medical Association, Members Handbook, 1965, p. 59.

- General Medical Council, Functions, Procedure, and Disciplinary furisdiction, 1966. G.M.C., London.
}

tatingly condemned to what may be deplored or merely regretted. On the fringe are matters of etiquette and good taste, which are largely for individual decision though still subject to the judgement of colleagues. But, at a time when both the State and public curiosity obtrude more and more upon the privacy of the citizen, most doctors would be unwilling to countenance any loosening of traditional professional reticence about things seen or heard in the course of medical practice. It would be most unfortunate if Lord Moran's book led the public to think otherwise.

\section{Immunization Against Poliomyelitis}

The incidence of paralytic poliomyelitis in Great Britain has steadily declined since immunization with the inactivated Salk-type vaccine began in 1956, and the decline was faster after the introduction of the Sabin oral poliovaccine in 1962 . This trend should continue if a high level of immunization is maintained. Unfortunately it is not being. The Chief Medical Officer of the Ministry of Health has recently drawn attention to this. ${ }^{1}$ By the end of $196571 \%$ of children born in 1963 and $65 \%$ of those born in 1964 had been immunized against poliomyelitis. Likewise the Scottish Home and Health Department ${ }^{2}$ records that $70 \%$ and $64 \%$ of infants born in 1963 and 1964 had been immunized by the end of 1965 . These rates mean that a substantial number of infants are not being protected. As we know from the experience of Hull in $1961^{3}$ and Blackburn ${ }^{4}$ last year, paralytic poliomyelitis can readily reappear in communities where the presence of susceptible, unimmunized individuals permits virus to spread. The effectiveness of poliovaccine is clear from the epidemiological records of countries where mass immunization is practised. From all these countries come reports of a sharp decline in the incidence of paralytic illness. Last year in the United States there were only 59 reported cases of poliomyelitis, of which 34 were paralytic. ${ }^{5}$ Of particular significance is the fact that $56 \%$ of these were in children of 4 years of age or younger and $59 \%$ had received no poliovaccine whatever. The record in Britain has been good, but in the epidemic at Blackburn last year of the 50 reported type I cases 25 were paralytic, and all these patients were either unvaccinated or inadequately vaccinated. ${ }^{6}$ Forty-three of the patients were adults. In Sweden and Canada poliomyelitis has been controlled by the large-scale use of potent inactivated vaccines.

In an ideal situation where $100 \%$ of the community had been immunized, poliomyelitis would be eradicated. Consequently every effort should be made to get as close to the target as possible. Three points require special emphasis. First, special attention should be placed on the immunization of infants in the first year of life. It should be carried out throughout the year. The second point is to ensure that children are reimmunized at the time of school entry.

C.M.O. 4A/66.

2 Circular letter from Scottish Home Department, 18 April 1966.

s Ministry of Health, Reports on Public Health and Medical Subjects, No. 7, 1963. H.M.S.O.

- Brit med $7,1965,2,542$

5 C.D.C. Weekly Reports, 1966, Vol. 14, No. 52, p. 442.

- Ibid., 1965, Vol. 14, No. 35, p. 324.

- Standing Medical Advisory Committee of the Ministry of Heal:h, Active Immunization Against Infectious Diseases, 1965. 
Thirdly, the absence of poliomyelitis from a community may lead to a false sense of security.

The oral poliovaccine used in Britain contains all three types of poliovirus. ${ }^{7}$ The recommended schedule is three doses of vaccine at intervals of about 4 to 6 weeks, starting at 6 to 7 months, after the primary course of triple vaccine has been completed. Alternatively, both triple vaccine and oral poliovaccine may be given simultaneously, the course starting at 3 months. This has the advantage of being easier from the administrative point of view and may result in a greater number of children being immunized. At present there is insufficient evidence to decide whether it is necessary to offer a reinforcing dose of oral poliovaccine in the second year of life, but when primary immunization has been completed before the baby's sixth month it is probably desirable to give a further dose of oral vaccine at 18 to 24 months at the time of the important reinforcing dose of triple vaccine. In order to ensure that immunity is maintained it is most important to give a reinforcing dose of oral vaccine at the time of school entry. This has the double advantage of maintaining immunity and providing a check on those who have escaped the primary immunization course in infancy. Adults who are likely to be at special risk, such as those travelling abroad to epidemic areas, would be well advised to take advantage of the simplicity of administration of oral poliovaccine in having a booster dose. This applies particularly to persons who were immunized with inactivated vaccine some years previously.

There are few contraindications to oral poliovaccine. Like any immunization procedure, it should be postponed if the patient is ill. Patients on corticosteroid therapy need special consideration. It is probably best to withhold it from those on long-term therapy in high dosage, but each case should be considered individually. It is also advisable to withhold oral vaccine during the first four-months of pregnancy, though there is no evidence whatever that the live virus vaccine has any deleterious effect on the foetus. Immunization is better carried out before, rather than during, pregnancy. Few vaccines produce so few reactions as does oral poliovaccine, and its ease of administration recommends it to most young patients.

Continued vigilance is required to ensure that immunity against poliomyelitis is maintained, and all members of the profession, medical officers of health, general practitioners, and hospital doctors can help to see that it is.

\section{Research in Migraine}

The recent announcement of the formation of a Migraine Trust under distinguished medical guidance raises hopes that research into this baffling disease will be intensified. Lord Brain is the chairman of the Trust and Dr. Macdonald Critchley is one of the other trustees. ${ }^{1}$ This week Lord Brain and Lord Hill of Luton launched an appeal at the Royal College of Physicians for $£ 750,000$ to finance research into the disease. The Trust hopes to establish a sixteen-bed in-patient unit for the study of patients before, during, and after an attack. In addition, it suggests that research fellowships should be set up at different centres-probably five. With the help of the Medical Research Council an epidemiological survey into migraine has already started in the
Rhondda Valley, while another is planned for Scotland under the auspices of Glasgow University.

Previous research has been closely tied to attempts at therapy. Thus C. Tzanck's report ${ }^{2}$ of the efficacy of ergotamine tartrate in the relief of the disorder, followed by that of W. G. Lennox and T. J. C. von Storch, ${ }^{3}$ led J. R. Graham and $H$. G. Wolff ${ }^{4}$ to carry out their experiments on the mechanisms of migraine headache. Their view that the headache itself is due to vasodilatation is now generally accepted, as is the idea that ergotamine is effective because it counters the dilatation of the blood vessels. The reason for the nausea and vomiting, which is a feature of some attacks, is more obscure, and some doubt also exists about the precise cause of the prodromal visual and sensory phenomena. Most workers hold the view that these are due to a period of vasospasm preceding the dilatation, but some believe they may owe their origin to cortical excitation of a kind seen in epilepsy. The susceptibility of some sufferers from migraine to photic stimulation has been advanced in support of this theory, but the pace of evolution of an attack is not that of an epileptic seizure.

To these early basic findings A. M. Ostfeld and colleagues ${ }^{5}$ later added the discovery that during an attack of migraine a substance is elaborated locally, at least in the perivascular extracranial tissues, which damages these tissues and lowers the threshold to pain in them. These perivascular tissues contain increased amounts of one or more amino-acids during the attack of migraine. The chemical nature of this harmful agent is still unknown, and acetylcholine, histamine, serotonin, bradykinin, and neurokinin have all been considered possible. Recently serotonin has been thought the most probable candidate, and, since 1-methyl, D-lysergic acid butanolamide (methysergide, Deseril) was evolved as an inhibitor of the action both of histamine and of serotonin, F. Sicuteri ${ }^{6}$ tested its effects in treatment of the attack and prophylaxis. $\mathrm{He}$ found it of little value in relieving a headache once begun, but of benefit in the prevention of attacks. Reports on larger series of patients followed, ${ }^{78}$ and they showed the prophylactic efficacy of methysergide but also certain side-effects. These included such grave hazards as severe peripheral vasoconstriction and retroperitoneal fibrosis, ${ }^{9}$ which though infrequent are none the less alarming.

A second line of approach followed the successful treatment reported with progestogenic steroids. The contemporary favourite is 6- $\alpha$-trifluoro-methyl 17- $\alpha$-acetoxyprogesterone (Demigran), which appears to be rather more efficacious in Scandinavia than in other countries, a difference that may be due to prescribing in higher dosage. The use of progestogenic steroids stems from the reputed value of progesterone in the treatment of premenstrual migraine. However, Demigran is said to be helpful in all types of migraine in both men and women, ${ }^{10}$ a conclusion which seems only to confuse any rational interpretation of the physiological problems and

\footnotetext{
1 Brit. med. F., 1966, 1, 230.

2 Tzanck, A., Bull. Soc. méd. Hôp. Paris, 1928, 52, 1057. 3ennox, W. G., and von Storch, T. J. C., F. Amer. med. Ass., 1935,

Graham, J. R., and Wolf, H. G., Ass. Res. nerv. Dis. Proc., 1937, 18, Ostfeld, A. M., Chapman, L. F., Goodell, H., and Wolf, H. G.,
Psychosom. Med., 1957, 19, 199.

- Sicuteri, F., Int. Arch. Allergy, 1959, 15, 300.

' Graham, J. R., New Engl. f. Med., 1960, 263, 1273.

${ }^{8}$ Friedman, A. P., and Losin, S., Arch. Neurol. (Chic.), 1961, 4, 241.

- Brit. med. 7., 1966, 1, 755.

10 Lundberg, P. O., Int. Congr. Neurol. Sci., 1965, 4, 407.

1 Miller, H. G., Prescribers fournal, 1965, 5, 74.
} 